\title{
UMA VISÃO PRELIMINAR DOS ESTUDANTES DA UNISINOS
}

\author{
Luiz Inácio Gaiger \\ Eliane Conceição Santos Locks \\ Cleonice Silva
}

Esse trabalho integra uma pesquisa coordenada pelo Núcleo de Estudos da Religião da UFRGS, da qual participaram Universidades do Rio Grande do Sul, Rio de Janeiro e Minas Gerais. Seu objetivo principal é caracterizar as representações e as vivências religiosas dos estudantes de Ciências Sociais, indagando sobre as possiveis peculiaridades advindas do fato de serem alunos desse curso e de o fazerem a partir de condições e em circunstâncias sociais e acadêmicas diferenciadas.

Muito embora se trate de comparar estudantes e cursos, segundo parâmetros de natureza social e institucional, uma questão de fundo, motivadora inicial da pesquisa, permanece: em que medida a formação universitária em foco atua como expressão de uma convergência identitária, ou como vetor que a provoca e alimenta, facultando que adquira traços próprios na forma como os estudantes se representam o mundo, a política e a religião? Foi precisamente por perceberem um estilo específico (ainda que variável e, portanto, não monolítico), a um dado momento, entre os estudantes de Ciências Sociais, e por identificarem mudanças posteriores, decorrentes de outra situação histórica e, no entanto, relacionadas em sua medida e forma à condição de estudantes, que reflexões registradas em um trabalho, já há alguns anos (NOVAES, 1994), serviram de inspiração e guia para essa investigação.

Luiz Inácio Gaiger é Doutor em Sociologia e professor da UNISINOS; Elaine Locks e Cleonice Silva são Bacharéis em Ciências Sociais, pela Universidade do Vale do Rio dos Sinos - UNISINOS.

Debates do NER, Porto Alegre, ano 2, n. 2, p. 117-132, agosto de 2001 
Aceitá-la como hipótese de trabalho e averiguar essa possivel especificidade - "em idênticas condições sociais e históricas, os alunos de Ciências Sociais não seriam exatamente como quaisquer outros" - significa ir em busca de sua caracterização cultural e religiosa, de sua compreensão à luz das condições sociais e das trajetórias desses sujeitos estudantes; significa também tomá-los como provável grupo indicador das mudanças gerais que perpassam a sociedade, alterando representações e práticas no campo religioso e no campo político. Ou seja, se nos anos 70, os futuros cientistas sociais, de modo próprio ou mais do que outros, encontraram na ciência e na política os elementos substitutivos de representações religiosas em retirada, e por isso delas se desembaraçaram, e se porventura já não o fazem atualmente, algo mais profundo poderá ter mudado na equação ciência - política - religião e no significado de cada um dos seus termos. Os tempos recentes, afinal, têm sido de crise da razão e da ciência, de descrédito na política, de pluralidade e expansionismo religioso, de misticismo e de renovação de Igrejas tradicionais. Compreender o que se passa com esses estudantes, sob essa ótica, pode, assim, ser instrutivo sobre o que ocorre de maneira mais ampla e mais difusa na sociedade.

Naturalmente, chegar a tanto exigiria o concurso de técnicas de pesquisa múltiplas e complementares, além de uma análise histórica altamente fundamentada, talvez não de todo possivel, dada a falta de dados. O estudo que apresentamos aqui, em caráter preliminar, tem objetivos bem mais modestos. Ele visa apresentar resultados da primeira fase de análise, basicamente descritiva, do questionário aplicado aos alunos da UNISINOS. Deseja-se, quando muito, identificar as características predominantes nesse conjunto de indivíduos, esboçar um quadro compreensivo de suas representações e comportamentos e lançar novas pistas de análise a serem examinadas posteriormente.

$\mathrm{Na}$ UNISINOS, foram aplicados 74 questionários, no se- 
gundo semestre de 1999, em um universo de 191 alunos matriculados. A aplicação e o tratamento dos dados serviram como exercício prático para os alunos da disciplina de Pesquisa III. Dadas as dificuldades de realizar a aplicação numa amostra perfeitamente aleatória, procedeu-se a uma amostragem por quotas, da seguinte forma: escolha de duas disciplinas de início do curso $\left(2^{\circ}\right.$ e $3^{\circ}$ semestres $)$, duas intermediárias $\left(4^{\circ}\right.$ semestre) e três avançadas $\left(5^{\circ}\right.$ e $6^{\circ}$ semestres), distribuindo-se, em seguida, número idêntico de questionários por aplicador, a cada um cabendo uma das turmas.

O tamanho estatisticamente insuficiente da amostra acarreta um problema de sub-representatividade, que imaginamos vir a corrigir-se na totalização das diferentes universidades, uma vez guardadas as mesmas proporções entre amostra e população local representada. Desse modo, as inferências a partir dos 74 indivíduos entrevistados devem ser feitas com cautela e, quando se referem a pequenos números, necessitam de evidências suplementares para efeitos de interpretação mais conclusiva. Avançar nessa direção há de requerer uma exploração ulterior, possivelmente multivariada, das questões que se mostrarem significativas.

\section{O perfil dos estudantes da UNISINOS}

Conforme esclarecemos anteriormente, para garantir que a aplicação do questionário fosse o mais bem distribuída entre os alunos do curso de Ciências Sociais, selecionamos disciplinas vinculadas a diferentes semestres da grade curricular. Essa forma de amostragem alcançou resultados satisfatórios. Primeiramente, convém ter em vista, conforme a tabela 1, que há uma fração de estudantes ingressados no curso há bastante tempo, evidenciando o fenômeno característico dos cursos noturnos e pagos, de alongamento dos estudos, por força de compatibilizá-los com o trabalho, com outros compromissos pessoais e familiares ou, ainda, indicando situações de ingresso em um segundo curso uni- 
versitário. No quesito "tempo decorrido desde o ingresso no curso", a UNISINOS apresenta os mais altos coeficientes (STEIL et al., 2001: 4) ${ }^{1}$.

Por outro lado, entre os estudantes que compõem o grosso da amostra, ingressados nos últimos cinco anos (19941999), a distribuição ano a ano assume os traços de uma curva normal, com elevação no biênio 1996-97, portanto, com uma preponderância de alunos há três anos no curso, contra um tempo médio de estudos superior a cinco anos.

\begin{tabular}{c|cc} 
Ano Ingresso & Freqüência & Percentual \\
\hline $1974-1993$ & 9 & 12,2 \\
$1994-1999$ & 65 & 87,8 \\
1994 & 5 & 6,8 \\
1995 & 7 & 9,5 \\
1996 & 17 & 23,0 \\
1997 & 16 & 21,6 \\
1998 & 14 & 18,9 \\
1999 & 6 & 8,1 \\
Total & $\mathbf{7 4}$ & $\mathbf{1 0 0}$ \\
\multicolumn{2}{c}{ Tabela 1 - Ano de Ingreso no Curso }
\end{tabular}

Observando-se a questão sob o prisma do semestre em que os estudantes estimam encontrar-se, os dados são consistentes: a distribuição é relativamente homogênea entre os oito semestres do curso, com explicável redução no primeiro e no último semestre, cujas disciplinas específicas não entraram na amostra ${ }^{2}$. Embora as respostas tenham um

\footnotetext{
${ }^{1}$ Pequenas diferenças entre as cifras publicadas pelo NER e por nós devemse ao fato de que calculamos os percentuais de resposta em relação ao total de entrevistados, não aos que responderam cada questão.

${ }^{2}$ Em razão de que as turmas são mistas ou pequenas e os alunos desses semestres costumam adiantar ou atrasar disciplinas de semestres intermediários.
} 
cunho subjetivo, senão aleatório, posto que o cálculo exato exige conjugar uma série de variáveis, não deixam de atestar uma dispersão adequada dos respondentes entre os alunos matriculados no curso de Ciências Sociais.

Os municípios de residência dos entrevistados abrangem a região metropolitana de Porto Alegre e o Vale dos Sinos, com predominância dos centros urbanos maiores, tal como se observa no conjunto de estudantes da UNISINOS ${ }^{3}$. Cerca de 51\% moram em cidades de origem e formação teutobrasileira, típica do Vale e da Encosta da Serra. Essas características étnicas refletem-se claramente na raça ou cor auto-atribuídas pelos estudantes, com larga predominância da cor branca $(87,8 \%)^{4}$.

\begin{tabular}{l|cc} 
Cor / Raça & Freqüência & Percentual \\
\hline Branca & 65 & 87,8 \\
Negra & 1 & 1,4 \\
Morena & 1 & 1,4 \\
Mista/Mestiça & 4 & 5,4 \\
Brasileira & 2 & 2,7 \\
Parda & 1 & 1,4 \\
Total & $\mathbf{7 4}$ & $\mathbf{1 0 0}$
\end{tabular}

Tabela 2 - Cor ou raça auto-atribuida

\footnotetext{
${ }^{3} \mathrm{O}$ mesmo se verifica na ligeira predominância $(54,1 \%)$ do sexo feminino na amostra.

${ }^{4}$ A questão ficou em aberto, segundo Steil et al. (2001: 6), "para que se expressasse a diversidade de gradações de cor, que surge quando a categorização das respostas é deixada a posteriori”. O predomínio da cor branca é coerente com os dados do IBGE (1991), em que 86,9\% da população gaúcha assim se reconhece.
} 
No que tange à composição etária, desponta uma singularidade dos cursos oferecidos à noite pela universidade: exatos 50\% dos entrevistados possuem 30 anos ou mais, havendo $12,2 \%$ com idade superior a 39 anos e, no outro extremo, apenas 23\% com até 22 anos de idade. Além do fenômeno de alongamento dos estudos, dado o perfil predominante de estudantes trabalhadores, pesam nesse sentido situações de reingresso, de volta tardia aos estudos ou de ingresso em idade avançada, nesse caso motivado às vezes por puro interesse intelectual. O jovem universitário típico das universidades públicas representa uma parcela menor dos estudantes de Ciências Sociais da UNISINOS. Essa diversidade geracional, em que convivem jovens e adultos, torna complexa a análise das predisposições sócio-culturais dos estudantes, das influências que sobre elas pesam e dos valores e comportamentos que lhes correspondem.

As fontes de renda e provento dos estudantes o confirmam com nitidez: enquanto somente $20,3 \%$ o restringem à família, sem exercerem atividade remunerada, 59,5\% dependem do emprego, a que se somam outras modalidades intermediárias de sustento próprio. O ingresso no mercado de trabalho, por conseguinte, não é posterior aos estudos universitários, mas tende a antecedê-lo, inclusive como forma de viabilizá-los.

$O$ perfil escolar e profissional dos pais insere-se perfeitamente nesse mesmo contexto. Entre os pais, 58,1\% não alcançaram os estudos secundários; entre as mães, 64,9\%. Assim, somente $8,4 \%$ dos pais exercem profissões que requerem ordinariamente estudos superiores $(13,5 \%$ os possuem), caindo esse percentual no caso das mães, em que se verificam índices altos de dedicação exclusiva aos afazeres domésticos (42\%) e, numa fração menor (12,2\%), a presença de professoras e educadoras.

Um dado de interesse refere-se ao estado civil declarado. Não obstante a composição etária elevada (mediana igual a 30 anos), os percentuais de casados $(31,1 \%)$ e ex-casados 
$(8,1 \%)$, a rigor, não são altos. Ou existe uma preferência inconfessa por outras formas de união estável (apenas 4,1\% dos estudantes o apontou) ou os indivíduos estão retardando o momento de casarem, o que, de um modo ou de outro, denota alguma tomada de distância do casamento na sua ace pção e função convencionais, para não dizer de sua valoração cristã e sacramental. Secularização e autonomia individual, processos que se conjugam em nossos dias, talvez componham o pano de fundo a dar sentido a esses comportamentos.

\section{Politização e militância em novos tempos?}

Quando perguntados sobre a motivação que os conduziu ao curso de Ciências Sociais, os estudantes entrevistados apontaram majoritariamente sua preocupação com os problemas sociais (34\% dos motivos mencionados) e seus interesses pela política $(20,9 \%)$. Essas alternativas foram escolhidas, respectivamente, por $73,2 \%$ e $45,1 \%$ dos alunos que responderam à questão (de escolha múltipla). Num outro gradiente, motivos de ordem pessoal e familiar, somados, correspondem a 38,5\% das respostas dadas. Por um lado, nota-se a permanência da vocação política desses estudos; por outro, que tal sensibilidade não é inconciliável com razões de natureza propriamente subjetiva, diante das quais podem ficar em segundo plano ou, em todo o caso, vinculadas à existência de interesses pessoais $(29,4 \%$ das respostas, $63,4 \%$ dos respondentes).

Essas variações devem ser compreendidas no contexto de um grau razoável de envolvimento social dos estudantes. Embora somente 56,8\% dos entrevistados tenha indicado modalidades de engajamento social e político, os percentuais ficam acima da média das demais universidades (STEIL et al., 2001: 17). Secundando a participação no próprio movimento estudantil (24,6\% das citações), aparecem os grupos vinculados a Igrejas $(21,3 \%)$, os movimentos ecológicos e 
ambientalistas (18\%), os sindicatos $(11,5 \%)$ e as associações de bairro $(9,8 \%)$. Movimentos de cooperativas, de gênero e étnicos completam o leque, sinalizando a presença de formas de mobilização social que ganharam impulso no último decênio.

Quando se entra diretamente no terreno político-partidário, as opiniões apontam um marcado perfil de esquerda. Assim, 70,3\% votaram em Lula nas últimas eleições presidenciais, fato associado à existência de uma parcela expressiva, de $63,5 \%$, que afirma possuir uma identificação partidária. Dos 47 estudantes que o fizeram, 45 apontaram partidos costumeiramente agrupados na Frente Popular. Essa tendência à esquerda caracteriza os alunos do Rio Grande do Sul (STEIL et al., 2001: 16).

\begin{tabular}{l|cc}
\multicolumn{1}{c|}{ Partido } & Freqüência & Percentual \\
\hline PT & 39 & 52,7 \\
PC do B & 4 & 5,4 \\
PMDB & 1 & 1,4 \\
PSB & 1 & 1,4 \\
PV & 1 & 1,4 \\
Sem identificação & 27 & 36,5 \\
Não respondeu & 1 & 1,4 \\
$\quad$ Total & $\mathbf{7 4}$ & $\mathbf{1 0 0}$
\end{tabular}

Tabela 3 - Identificação com partidos políticos

Alguns dados complementares levam-nos a matizar essas cores, a perceber que o ambiente politizado em que convivem os estudantes não exclui outras preferências e atitudes, que certamente seriam consideradas destoantes (ou simplesmente alienantes) em tempos não muito remotos. 
Assim, na resposta à questão sobre "os livros que marcaram a sua vida", dentre uma variedade de gêneros despontam treze citações de obras de caráter político, seguidas de nove de cunho espiritual, de auto-ajuda ou místico. Ao serem perguntados sobre o último livro de auto-ajuda que leram, 48,6\% dos estudantes lembraram-se do título, indicando serem essas leituras um hábito, tanto mais que, para 17,5\% deles, o último livro lido foi, precisamente, de auto-ajuda ou espiritualid ade.

Outros tempos e outros ventos, em que a politização perde seu sentido totalizante e já não parece alimentar o estilo de militância comum entre os universitários de 15 anos atrás. Referimo-nos, principalmente, à pertença a agrupamentos políticos e para-partidários, determinados por uma orientação ideológica de extração marxista, hermética e refratária a perspectivas compreensivas que não possuíam o mesmo selo de origem; ademais, inibidora de atitudes impulsionadas pela busca e valorização da individualidade, pelo seu suposto viés ou caráter burguês e anti-socialista. Contra isso, os atuais estudantes demonstram abertura a diferentes vias de busca pessoal de significado e de compromisso consigo e com a coletividade. A mesma postura aparece, talvez com maior transparência, em seus posicionamentos diante da religião.

\section{Tradição e abertura religiosa}

A exemplo das questões sobre a política, as opiniões proferidas sobre a religião encerram uma dupla subjetividade, pois trata-se de estudantes dizendo o que pensam pessoalmente de si mesmos. Por conseguinte, o que está em jogo na apreciação das respostas é o modo como representações e práticas referidas ao religioso aparecem em suas percepções, o que faz sentido, visto que, para serem instituintes, os elementos religiosos necessitam estar presentes de antemão como um dado cultural e simbólico ou como um esta- 
do de consciência.

A tabela 4 demonstra que poucos consideram-se não crentes, contra $89,2 \%$ que afirmam algum tipo de vínculo com a religião, mesmo se não professando um credo específico. Perguntados diretamente, $77 \%$ responderam possuir uma religião, percentual dos mais altos no comparativo com as outras universidades (média de 52\%). O fato, como veremos, não retira a diferença de sentido entre assumir-se como crente e aderir a uma confissão religiosa determinada, em seguimento aos seus respectivos preceitos, institucionalmente consagrados.

\begin{tabular}{l|cc} 
& Freqüência & Percentual \\
\hline Ateu & 3 & 4,1 \\
Religioso & 55 & 74,3 \\
Agnnóstico & 2 & 2,7 \\
Sem religião & 11 & 14,9 \\
Não respondeu & 3 & 4,1 \\
Total & $\mathbf{7 4}$ & $\mathbf{1 0 0}$
\end{tabular}

Com essa ressalva, pode-se constatar a predominância da declaração católica $(62,1 \%$ das respostas, com $27,3 \%$ na condição de católico praticante). Segue-se a confissão espírita, com 12,1\%, um fenômeno algo inusitado, também verificado em outras universidades (STEIL et al., 2001: 9). Singularizando o perfil da UNISINOS, a terceira religião apontada é o protestantismo histórico, com 10,6\%.

A análise da religiosidade dos pais, tal como vista pelos estudantes, traz elementos esclarecedores: $80,3 \%$ dos pais foram classificados como católicos, $29,5 \%$ como praticantes. 
No lado materno, o total desce para 75,3\%, embora o percentual de mães católicas praticantes suba para 41,1\%. As características históricas do Vale dos Sinos, centro da imigração alemã no RS, explicam, por outro lado, os altos indices de pais protestantes: 13,5\%, aproximadamente. Há, portanto, uma perda de catolicidade de pais para filhos. Não sendo muito acentuada, evidenciaria que a transmissão religiosa se faz ainda de maneira razoável. No protestantismo histórico, essa eficiência seria ainda maior.

Nesse quadro relativamente estável, do ponto de vista da identificação religiosa, o fato mais contrastante, na passagem de uma geração para outra, é a proporção de estudantes de confissão pentecostal $(9,1 \%)$, diante do mínimo registrado entre os pais (apenas dois casos). A cifra fica bem acima das demais universidades (média de 2,3\%). Considerando-se, ademais, que $81,4 \%$ das respostas apontou a família como principal fator de influência na escolha de sua religião, estariamos identificando um provável flanco na matriz religiosa tradicional, com indícios de um processo de trânsito religioso para o pentecostalismo. O fenômeno, no atual contexto brasileiro, obviamente nada teria de original. Ainda assim, demanda um estudo pormenorizado para a compreensão das circunstâncias em que ocorre, nesse caso preciso $^{5}$.

De todo modo, dado que o trânsito religioso pressupõe algum distanciamento da religião anterior, ou um declínio ao menos momentâneo dos compromissos religiosos assumidos, é significativo verificar que apenas $29,7 \%$ dos estudantes declaram participar rotineiramente da vida religiosa de sua Igreja, enquanto $47,4 \%$ o fazem eventualmente (ou não possuem religião). Ao mesmo tempo, 37,8\% admitem participar de outra religião, dos quais somente $17,8 \%$ de modo re-

\footnotetext{
${ }^{5}$ Há que se considerar que a modéstia absoluta das cifras desautoriza raciocínios conclusivos. O mesmo vale para a adesão a religiões afro-brasileiras e orientais, de pequena penetração.
} 
gular, e 58,5\% em caráter eventual. Mais do que uma dupla ou tripla filiação, estariamos diante de uma pluralidade religiosa de contornos variáveis e dinâmicos, motivada talvez antes por circunstâncias (familiares ou outras) e, isto sim, sustentada por uma atitude pessoal de autonomia frente às religiões instituídas.

A orientação desta abertura religiosa parece seguir diferentes caminhos. Por um lado, em 48,9\% dos casos são as próprias religiões históricas, católica e protestante, que aparecem como sendo a segunda (ou terceira) religião, o que pode ser atribuído à força de indução (e recondução) da matriz cultural e religiosa predominante na região, já pelas não infreqüentes uniões conjugais entre católicos e protestantes. Numa outra direção, aparece a religião espírita (20\%), num sinal de que o processo de conversão antes registrado tende a continuar. Por fim, são referidas religiões afro-brasileiras e orientais $(24,4 \%)$, sugerindo uma busca de novos caminhos, seja via recuperação de raízes identitárias, na esteira dos movimentos de raça e etnia, seja nas trilhas do esoterismo, isto é, da busca daquilo que provém, justamente, de outros lugares.

Quando a questão é colocada de forma mais branda, $33,8 \%$ dos entrevistados confessa ter curiosidade por alguma (outra) alternativa religiosa, nesse caso para além, ao que se pode supor, $d a$ ou das religiões já conhecidas ou praticadas. As alternativas em tela são as mais variadas, com destaque para o espiritismo e o budismo (ambos com 9,5\%). Somadas, as preferências de cunho místico e esotérico atingem $44 \%$ dos estudantes que manifestaram possuir tal curiosidade. Tradição e disposição para o encontro de novos referentes não são realidades contraditórias.

Em resultado dessa combinação entre uma matriz religiosa histórica, processos de trânsito religioso em curso, ainda que em ritmo moderado, e permeabilidade ou busca pessoal ativa de novas orientações, tem-se um inventário extenso de representações e práticas, às quais a adesão dos estu- 
dantes da UNISINOS é quase invariavelmente superior à média geral das demais universidades ${ }^{6}$.

\begin{tabular}{l|cc} 
Crenças & Freqüência & Percentual \\
\hline Acredita em Deus & 59 & 79,7 \\
Acredita em J esus Cristo & 47 & 63,5 \\
Acredita em Virgem Maria & 29 & 39,2 \\
Acredita em Santos & 25 & 33,8 \\
Acredita em Anjos & 37 & 50,0 \\
Acredita em Espíritos & 32 & 43,2 \\
Acredita em Duendes ou Gnomos & 7 & 9,5 \\
Acredita em Demônios & 14 & 18,9 \\
Acredita em Entidades ou Orixás & 15 & 20,3 \\
Acredita em Vida após a morte & 29 & 39,2 \\
Acredita em Reencarnação & 25 & 33,8 \\
Acredita em Energias/Aura & 25 & 33,8 \\
Acredita em Astrologia/Horóscopo & 13 & 17,6
\end{tabular}

Tabela 5 - Crenças religiosas

O perfil religioso predominante nos estudantes da UNISINOS explica o número elevado de crentes nas figuras teológicas basilares das religiões cristãs históricas (Deus, Jesus Cristo), não obstante, curiosamente, fique esse número aquém do total de adeptos dessas confissões. Sinais desta, digamos, heterodoxia religiosa, podem estar na crença significativa em entidades e orixás, em contraste com a inexpressiva parcela de seguidores declarados de religiões afro-brasileiras, crenças em convivência provavelmente harmoniosa com elementos (correspondentes) do próprio catolicismo. Elaborações sincréticas dessa ordem são comuns no Brasil, mas sua manifestação causa alguma surpresa na região e no meio social em tela. No mesmo sentido, a tabela

${ }^{6}$ As exceções, ligeiramente a menos, dizem respeito à vida após a morte e a energias ou aura. 
acima indica certa equiparação das crenças em elementos típicos da cosmologia católica (Virgem Maria, santos) com elementos subsidiários ou de sentido difuso (anjos, espíritos). Estes últimos parecem antes estar em linha de continuidade com a temática da passagem e transcendência, em voga na espiritualidade contemporânea (a par do próprio espiritismo) e, por outro lado, com figuras características da Nova Era e de seus componentes místicos (demônios, gnomos, duendes, astrologia, energias, etc.).

\section{Considerações finais}

Ao cursar as cadeiras de Ciências Sociais, particularmente de Antropologia, alguns estudantes da UNISINOS realizam trabalhos etnográficos em candomblés, casas de umbanda, centros espíritas, igrejas pentecostais e casas de terapias alternativas, entre outras. Mostram interesse pessoal em conhecer outras crenças e, como no caso de um aluno estudioso do espiritismo, tornam-se às vezes freqüentadores ou adeptos. Não deixam de imediato sua religião de origem, geralmente católica, e vivem períodos de conflito interior.

Esse comentário serve para dizer que, nos dias de hoje, a prática acadêmica do curso talvez mais estimule do que iniba a sensibilidade espiritual dos estudantes e sua aproximação com o universo religioso, como estudiosos e como pessoas. A gradativa incorporação do conhecimento e o domínio das suas mediações, por força de deixarem visível a naturalização da cultura e a reificação das crenças, levam à relativização das diversas alternativas religiosas, sem contudo retirar a legitimidade do dado religioso como tal e, principalmente, da busca interior de sentido, para além do racionalismo científico.

Essa impressão deixada pela convivência diária com os estudantes e pela reflexão propiciada pela experiência da pesquisa, ainda que correta, necessitaria naturalmente de 
explicações, pois, ao que se sabe, nem sempre foi assim. Dos dados colhidos e já comentados, sabe-se que sugerem um cenário consistente, como se permitindo aos estudantes formular novos arranjos em suas representações e práticas religiosas, segundo seu arbítrio pessoal, sem necessitar demarcarem-se previamente de seus vínculos de origem e distanciarem-se de toda religião. Ou seja, o desvio da secularização, como impugnação do papel cultural e subjetivamente integrador da religião, torna-se por assim dizer dispensável, embora por outro lado esteja presente, na medida em que confere maior autonomia moral e religiosa aos indivíduos. A impugnação do religioso não ocorre aqui na mesma proporção das outras universidades, mas tampouco encontra-se contida por uma alguma fixação religiosa em moldes tradicionais. Talvez jamais tenha ocorrido, mesmo à época em que ciência e racionalidade eram apreendidas antagonicamente à religiosidade (NOVAES, 1994). Restaria ver quão diferentes são esses estudantes entre si e por quais trajetórias e opções alcançam gerir as suas vidas. Sabemos por ora que, entre eles, a presença do religioso é simplesmente maior do que se poderia esperar: no percentual de católicos, de crentes em geral, de crescimento do pentecostalismo, de crenças em figuras e símbolos religiosos, na curiosidade, enfim, de conhecer outras religiões e novos caminhos providos de significad o.

\section{Referências bibliográficas}

IBGE. Cor ou Raça. População residente no RS em 1991. http://www.sidra.ibge.gov.br/cgi-bin/prtabl/pcuf (10/10/ 2000).

NOVAES, Regina. Religião e politica: sincretismos entre alunos de ciências sociais. Comunicações do ISER. Rio de Janeiro: 1994. 
SPAEMANN, Robert. Liberdade, Secularização e Banalidade. Entrevista realizada no Vatica no em 31/10/91. http:// www.hottopos.com (09/10/2000).

STEIL, Carlos Alberto; ALVES, Daniel; HERRERA, Sonia Reyes. Religião e politica entre os alunos de Ciências Sociais: a definição de um perfil. Porto Alegre: UFRGS, 2001. 